\title{
Improving Female Preventive Health Care Delivery Through Practice Change: An Every Woman Matters Study
}

\author{
Elisabeth L. Backer, MD, Jenenne A. Geske, PhD, Helen E. McIlvain, PhD, \\ Diane M. Dodendorf, PhD, and William C. Minier, MD
}

Background: The levels of breast and cervical cancer screening in Nebraska primary care remain suboptimal despite awareness of their importance, and despite implementation of the Every Woman Matters program to assist low-income women. The GAPS model was used to develop a practice-based intervention to identify and reduce barriers to delivery of breast and cervical cancer screening services.

Methods: Seven primary care practices actively participated in this multimethod case study. A research nurse collected data and facilitated the intervention process at each site. Qualitative data from field notes, patient encounters, and in-depth interviews of physicians and key informants were collected to describe the process of Papanicolaou and mammogram service delivery, and to identify barriers/facilitators to screening, and potential change areas. Chart reviews provided information regarding the preintervention and postintervention identification/execution of Papanicolaou smears and mammograms. Qualitative and quantitative analyses led to individual practice case studies. Cross case comparisons identified common themes.

Results: The individual practice plans for change had many commonalities, ie, developing screening databases and reminder systems. The biggest differences involved practice contexts. Despite use of the GAPS model and a financial incentive to obtain "buy in" from providers and staff, change was difficult for all but 2 of the practices.

Conclusion: The complexity of practice context and its effect on change cannot be underestimated. Individual practice providers and staff are often unaware of the potential challenges, and unable/unwilling to overcome them. (J Am Board Fam Pract 2005;18:401-8.)

The practice of screening for disease has been shown to save lives, reduce health care costs, and reduce suffering. Periodic screening for breast and cervical cancer has been particularly effective in reducing the burden of disease in women. ${ }^{1-6}$ Even so, screening rates in many practices fall short of recommended levels, leaving patients at unnecessary risk. ${ }^{7,8}$ Barriers to screening exist at many

Submitted, revised, 14 April 2005.

From the Department of Family Medicine (ELB, JAG, HEM, WCM), and Munroe-Meyer Institute (DMD), University of Nebraska Medical Center, Omaha, NE.

Funding: Support for the original research came from the grant (to ELB), Early Detection and Control of Breast and Cervical Cancer Cooperative agreement (U57/ CCU706734-06), through the Nebraska Department of Health and Human Services "Every Woman Matters" Program.

Conflict of interest: none declared.

Corresponding author: Elisabeth L. Backer, MD, Department of Family Medicine, 983075 Nebraska Medical Center, Omaha, NE 68198-3075 (e-mail: ebacker@unmc.edu). levels including the patient, physician, and practice systems. ${ }^{9-12}$

Every Woman Matters (EWM), a state-run federally funded program, is designed to remove barriers to preventive breast and cervical cancer screening by raising public awareness of the risk and making screening more financially accessible to low-income women. Eligible women receive a clinical breast examination, mammography, and Papanicolaou smear test at reduced or no cost. The EWM program provides services to practices to aid in implementation of the program. However, even with this program, the level of breast and cervical cancer screening falls short of the ideal.

Numerous decades of trying to improve preventive service delivery have shown that there are no magic bullets ${ }^{13,14}$; most interventions to alter physician and practice behavior have shown only modest success. ${ }^{15}$ Systematic reviews of change strate- 
gies recognize practices as complex systems and call for more effective and complex strategies that assist practices in initiating and sustaining change. ${ }^{16}$ Changing practice behavior entails teamwork among clinicians and staff, requires flexibility and willingness to change, and should be based on individualized interventions based on each system's unique and dynamic pattern. ${ }^{15,17}$ The GAPS model is based on these concepts. Using the GAPS model to enhance preventive care and modify office operations, we involved office staff at each step: goalsetting, assessing existing routines, planning the modification of routines, and providing support for these improvements. ${ }^{17}$

Our practice-based intervention study was designed in collaboration with the Nebraska Health and Human Services EWM Program to help individual practices identify barriers to their delivery of breast and cervical cancer screening services, develop plans for reducing barriers, and encourage provision of the EWM program to low income patients. We hypothesized that individualized, facilitated interventions could significantly increase the rates of up-to-date mammogram and Papanicolaou test screening in these practices.

\section{Methods}

\section{Design}

We used a qualitative case study design to describe the process of change that occurred in sample practices. Quantitative data from chart audits were used to measure changes in the number of mammogram and Papanicolaou tests. The study protocol was approved by the University of Nebraska Medical Center Institutional Review Board (028-98-FB).

\section{Sampling}

A maximum variation sample of 7 practices resulted from our sampling strategy to provide data from a variety of practice types. ${ }^{18}$

After identifying all Nebraska primary care practices enrolled in the EWM program that accepted new patients, we eliminated practices participating in other departmental studies, those that had participated in our pilot study, and those situated beyond a 100-mile radius of Omaha. After assembling a numbered list of 100 clinics, we randomly selected a starting number. The clinic corresponding to this number, along with every additional twelfth clinic listed, was chosen until 7 clinics were enrolled.

Participating clinics were advised of the study's purpose, and during the informed consent process, providers and staff at participating clinics agreed to 1) allow the field researcher access to the clinic site, staff, patients, and medical charts for review; and 2) actively participate in the development and implementation of a plan to improve and increase the delivery of these services.

\section{Data Collection}

After obtaining informed consent, a research nurse field worker entered each site for data collection using the following protocol.

\section{Baseline Data Collection}

This took place during 2 visits over a 1-month period. Data consisted of the following: 1) observational field notes regarding the practice environment, activities related to Papanicolaou smear and mammogram screening, and adult female patient encounters ${ }^{19,20}$; 2) audio-taped interviews with physicians and key staff ${ }^{21,22}$; and 3) chart reviews of the last 100 female patients between the ages of 19 and 64 seen in the clinic. These data were chosen because they would enhance our understanding of interactional patterns among individuals (physicians, staff, and patients), the activities related to Papanicolaou smear and mammogram screening, and the attitudes of the physicians and staff toward change. From these data, the analysis team would be able to determine practice strengths and weaknesses, and identify barriers to change. The field worker used approximately the same approach and time frame at every practice site.

\section{Practice Feedback and Action Plan Development}

On completion of baseline data collection, a feedback session was scheduled with the physicians and staff. The extent to which physicians and staff participated in these sessions varied by practice site. Feedback was given on rates of delivery of Papanicolaou smears and mammograms based on information gathered during the chart audits and on observations related to practice barriers and strengths. Participants were encouraged to identify potential system changes that would improve their screening rates and develop an action plan for change. 
Over the next 1 to 3 months, depending on the practice, the action plan was developed by the physicians/staff and fieldworker. It involved 2 to 4 specific behavioral goals they wanted to implement, the concrete steps to accomplish each goal, and a specific person responsible for each goal. Practices were encouraged to contact the fieldworker as needed for assistance in the development and implementation of their plan.

\section{Follow-Up}

The fieldworker returned to the practice at approximately 4, 8, and 12 months postbaseline to assess progress on the action plan and provide encouragement and assistance. Observational field notes dictated after each visit outlined the progress made by the practice and noted process issues affecting progress. At the 12-month follow-up, chart reviews were conducted on the last 100 female patients seen in the clinic between the ages of 19 and 64 .

\section{Data Analysis}

Our analysis team consisted of a behaviorist, a family physician, and a research methodologist experienced in qualitative and quantitative analysis methods. Qualitative data from each practice were initially read and analyzed individually. Notes were made regarding the practice system strengths and weaknesses, current protocols and system barriers, the action plan and any progress made at the 4-, 8-, and 12 -month visits. The team then met to develop a case study for each site describing the practice and summarizing the key themes defining the practice's process of change.

Quantitative data from the chart audits were analyzed using $\chi^{2}$ goodness of fit tests to determine whether significant improvements were achieved over the course of this study with respect to the performance and documentation of Papanicolaou smears and mammograms.

In the final analyses, commonalities were explored across case summaries. Of particular interest were changes in breast and cervical cancer screening rates; the extent of implementation of the action plan; the practice's perception of their accomplishments; and common themes among the factors defining change among the practices.

\section{Results}

Part A of this section contains information from the qualitative case study summaries and quantitative chart reviews. We made no interpretation of the objective "success" or "failure" of each practice's action plan, but noted the general attitude in the practice toward their results In part B, we identify and discuss commonalities and salient themes across practices.

\section{Part A: Case Studies of Practice Sites \\ Practice 1 \\ Context}

This was a new single-provider practice focused on building a financial patient base. Although the physician did not seem particularly prevention-oriented, his wife, the office manager, saw this project as an opportunity to provide services that would generate income and encourage patients to return for care. Our project offered a cost-free evaluation, advice, and assistance in improving clinical practice.

\section{Goals}

Practice 1 identified 4 target goals: 1) to develop a "summary of care" chart form making it easier for staff to identify patients in need of screening; 2) to develop a postcard system encouraging patients who obtained their screening elsewhere to ask to have their test results sent to the practice; 3) to increase patient awareness by making patient education materials more readily available; and 4) to create monthly computer-generated reminder lists of patients in need of screening.

\section{Results and Observations}

The staff worked closely together as a team and made steady progress on their plan. All 4 goals were accomplished. On chart audits, the practice significantly increased documentation of both mammograms and Papanicolaou smears (23.3\% to $60.4 \%$ and $17.6 \%$ to $67.8 \% ; P<.001)$, and updated women's medical records with respect to mammography and cervical screening.

The staff displayed an ability to work as a cooperative team toward goals that they saw as benefiting both themselves and the practice. This was due in large part to the office manager who led the effort, despite a lack of physician leadership.

\section{Practice 2}

Context

This rural, hospital-owned clinic had one physician and a part-time Physician's Assistant. The physi- 
cian championed participation in the study and enthusiastically generated ideas about how to improve things. His staff seemed less enthusiastic. The practice was owned by the hospital in a nearby town, which required major changes to be approved by the hospital first. Tension already existed between the hospital and the clinic regarding management issues before our study.

\section{Goals}

Practice 2 identified 3 target goals: 1) to develop a reminder system/database to notify them of patients needing screening; 2 ) to develop a prevention flow sheet allowing staff to more readily identify dates of needed service; and 3) to initiate community outreach to raise public awareness.

\section{Results and Observations}

The practice was eventually able to accomplish the first 2 goals. The database suggested in Goal 1 was identified as an important tool by the physician, and the staff reluctantly developed and implemented its use. A new prevention flow sheet was developed but required a lengthy approval process by the hospital. No one took active ownership of the third goal and it was not accomplished.

The physician's enthusiasm was not shared to the same extent by his staff. He decided the Goal 1 database was an important tool and then left it entirely to his staff to develop and implement without first assuring their buy-in. Although it was completed, the analysis team questioned whether or not the database would later be kept up and used by the staff. The physician did take ownership of the prevention flow sheet but the hospital's delays in approving the new sheet were burdensome and frustrating for him. The practice physician and staff seemed to have little investment in Goal 3, leaving it unaddressed without much further thought.

Despite the progress made on Goals 1 and 2, no significant quantitative differences were seen in the preventive service delivery rates. The analysis team surmised that this may have been because of a lack of "team buy-in" and/or the fact that it took so long to implement the goals that results weren't seen at the time of the last chart audit. The physician seemed to be the only one enthusiastic about change and was not able to create this enthusiasm in the other team members.

\section{Practice 3}

Context

This practice was an established high-volume, suburban multispecialty group, owned by a large hospital system. The clinic was a university teaching site with close ties to its institution, which in turn closely regulated its management and finances. The providers included 3 physicians and a nurse practitioner. Two of the physicians were gynecologists; the third was a family physician. Women's health care was the practice's focus. This orientation was reflected in their high baseline screening rates. Organizationally, each provider functioned independently, and a nurse manager led the support staff.

\section{Goals}

Practice 3 identified 3 target goals: 1) to develop a reminder system to inform patients that it was time for their screening; 2) develop a common fact sheet that all clinic providers would use to facilitate tracking the need for screening; and 3) to increase accessibility of patient education materials.

\section{Results and Observations}

Initial progress was made on the first 2 goals but this faltered over time and no progress was made on Goal 3. Their initial levels of screening were already relatively high, and no significant quantitative improvements were made.

Because each of the 3 providers functioned independently and the change activities did not fall within the scope of the providers, none of them seemed to really adopt the plan as their personal project. By default, the leadership role seemed to fall to the nurse manager, who did not actively guide the development and implementation of the work plan, nor encourage participation from interested staff. She seemed overextended in terms of other responsibilities and her managerial and leadership skills were underdeveloped. The staff lacked cohesion; the turnover rate was high, and there was noticeable disgruntlement related to salaries and support by the larger institution. This practice lacked any real champion for change despite their agreement to participate. Because initial chart reviews showed them to be doing a good job of screening, there was little impetus from either within or outside of the practice to energize additional effort. 


\section{Practice 4}

\section{Context}

This was a privately owned, high volume, singleprovider practice serving a rural, underserved, mainly minority population. The clinic was fairly new, had limited resources, and was striving for financial viability. The physician was originally from South America, and his staff consisted of family members who were trained physicians but not licensed to practice medicine in the United States. The medical assistant, his sister, was a radiologist; the clinic manager, his brother-in-law, was an orthopedic surgeon. The entire family had committed their lives to this small rural community and to improving the health care of the local immigrant Hispanic community.

\section{Goals}

Practice 4 identified 4 target goals: 1) to develop a computerized recall reminder system for patients; 2) to implement a "health passport" for Hispanic patients containing health information that could be carried to another provider if they moved; 3) to increase accessibility of patient education materials in the clinic; and 4) to increase community outreach.

\section{Results and Observations}

The practice accomplished all the objectives established to reach the 4 goals. Although there were no statistically significant changes in screening on chart audit, the trends for most of the quantitative variables were in a positive direction (Papanicolaou smears, $67.4 \%$ to $76.9 \%$; mammograms, $25 \%$ to $38.9 \%)$.

The practicing physician's behavior changed very little and he was minimally involved with the change plan. The support staff (primarily the clinic manager) embraced the plan for change with enthusiasm and efficiency, from its development to final implementation. The analysis team speculated that this was due to the underutilization of the clinic manager's skills/intellect, as well as his appreciation of a new challenge. It seemed likely that the changes would be sustained.

\section{Practice 5}

\section{Context}

This was a privately owned, solo practice in a rural area. The physician was very enthusiastic about having us come into the practice and had many ideas for change although he expected to retire in the next few years. He enjoyed conversing/communicating with his patients, which caused him to be chronically late. Despite the physician's enthusiasm, the practice overall felt stagnant, unfocused, and disorganized. There was little evidence of prevention being a priority.

\section{Goals}

Practice 5 identified 3 target goals: 1) to develop a calendar reminder system so that patients could be notified that screening was due; 2) to develop a chart flow sheet so that staff could identify when the next screening was due; and 3) to convert charts into a more practical format. The practicality of the third goal was questioned by the fieldworker but kept in the plan at the physician's insistence.

\section{Results and Observations}

There was some initial action taken on Goal 1 but no progress in the other 2 goals. There were no significant improvements noted in the chart audit analysis.

The lack of success seemed primarily because of a lack of effective leadership and carefully thought out goals. Although this physician liked brainstorming about changes that would improve practice, he showed little interest in the sustained effort necessary to accomplish them. His staff was continually urging him to expedite his encounters so that every patient could be seen, and they could leave the office at a reasonable hour. They seemed less optimistic and forthcoming about the possibility of making practice changes, possibly because of this constant tension and/or their past experiences of his inconsistent follow through.

\section{Practice 6}

\section{Context}

This practice was a rural, privately owned clinic with 2 providers, a physician and a nurse practitioner, located in a lower socioeconomic area. The clinic population experienced many of the psychosocial problems typical of communities with low incomes and few resources. Both providers displayed strong initial support for the project. Early impressions were of an efficient office interested in change, and forward-thinking enough to have developed a computerized database. As the study progressed, significant tension was apparent in the 
relationship of the physician and the nurse practitioner.

\section{Goals}

Practice 6 identified 4 target goals: 1 ) to revise the computer face sheet to collect necessary screening data; 2) to train staff to be more familiar with the EWM program and paperwork; 3) to develop reminder letters to be sent to patients; and 4) to promote community outreach.

\section{Results and Observations}

The practice completed Goals 1 and 2, partially addressed Goal 3, and did not address Goal 4. Their attitude toward these accomplishments was negated by the tension within the clinic. There were no significant improvements noted in the chart audit analysis.

This practice was dealing with larger, although less obvious, organizational problems at the time that they agreed to the project. The longer the fieldworker was in the practice the more it became evident that there was significant tension between the 2 providers. The nurse practitioner had taken over the role as "champion" of the plan and leading the effort of implementation. The support staff showed little enthusiasm for change, noting that they were already overcommitted; the office manager, who was loyal to the physician, supported the staff position. As the intervention progressed, the nurse practitioner became increasingly marginalized and eventually left the practice. This tension and conflict between leaders significantly limited the extent to which the practice members were able to cooperate as a team to reach practice goals.

\section{Practice 7}

\section{Context}

Practice 7 was an established rural, hospital-owned clinic with 3 physicians. This practice prided itself on seeing a high volume of patients; this corresponded with the high productivity expectation of the larger health system. During the project, one physician retired and 2 new physicians were hired. Two to 3 months into the project it became obvious to the fieldworker that there was significant resistance from the staff. The lead physician's response was to reduce the number of goals.
Goals

Practice 7 initially identified 2 target goals: 1 ) to increase community outreach; and 2) to develop a system, consisting of a database form and a Post-It note for the physicians to identify women eligible for screening. At a 4-month follow-up, the plan was modified to include only Goal 2.

\section{Results and Observations}

By the 12-month follow-up, progress had been made on all the original goals. One of the new physicians, interested in community outreach, started giving talks in the community and took ownership of the database form development. The lead physician took responsibility for the Post-It note and got it completed. There was, however, no increase in screening demonstrated in the analysis of the chart audit data.

Significant changes were occurring in this practice at the time of the project, including the hiring of a new clinic manager and 2 new physicians, and the retirement of one provider. The physician leading the group was very production and task-oriented. He made decisions about participating in this project but didn't take leadership of its accomplishment. Fortunately, a new physician, interested in preventive medicine, was hired and took a leadership role.

The office manager and staff passively resisted any efforts to include them in the change plan. The lead physician, although unwilling to drop out of the project, did little to encourage or facilitate staff participation.

\section{Part B: Commonalities and Themes}

Comparison across practices noted 7 common themes. First, although the goals generated by the practices were remarkably similar, the specific strategies used depended on the context of the practice and the resources available to them.

Second, the nature and extent of the change often depended on having a "champion" in the practice promoting and emphasizing the importance of the project and motivating others in the team. This leadership was marked by the ability to promote a strong sense of teamwork and the importance of everyone's effort.

Third, the burden of change fell primarily on the support staff. Without strong leadership and "buy in" at that level, change was unlikely to occur. 
Fourth, most practices were already operating at the capacity of their existing resources. However, none of the practices considered this when developing their action plan. Rather, it was a matter of adding one more thing to a system that was already operating at or beyond capacity.

Fifth, the focused intervention did provide an important service to some practices in the form of objective feedback, creative discussion, development of a specific plan, and ongoing facilitation.

Sixth, the 2 newer and, possibly, more unstable practices seemed to change to a greater extent, supporting the idea of practices as complex adaptive systems where change is more likely to occur "on the edge of chaos." 23,24

Finally, those practices owned by a larger hospital system were the least likely to change, possibly due in part to the inertia/stability created by the larger system.

\section{Discussion}

Our findings strongly support the concept of practices as unique, complex organizational systems. ${ }^{25}$ Practices varied significantly in their missions, their organizational flexibility, the individual personalities of their providers and staff, the resources available to the practice (and the control they had over their use), and their organizational cohesiveness, leadership, and ability to work as a team. ${ }^{17,26}$ Many of the practices seemed so overwhelmed with daily operational activities that the staff were resistant to the added efforts required for change. ${ }^{27}$

Most practices had to struggle against the inertia of their own stability whereas others had the added inertia of a larger, corporate system that actively discouraged individual change/instability. ${ }^{23,24}$ Practices 1 and 7 seemed to contain more instability or chaos within their systems; for Practice 1, being small and new, this seemed to result in greater flexibility. For Practice 7, the chaos of personnel changes seemed to create less flexibility especially on the part of the staff. Glieck (1987) in his book on chaos discusses the way in which disorderly/chaotic behavior creates anxiety within the system. In systems with leadership that can contain/ channel the anxiety, it can be turned into creativity, thereby generating greater complexity within the system (Practice 1); in more complex systems where leadership cannot contain the anxiety, this may lead to increased control by the system, thereby reducing instability/flexibility (Practice 7). Practice 4 seemed to be the one practice that had been underutilizing its own resources; through increased creativity and focused interventions, they were able to effectively promote change within their practice.

Despite the barriers that mitigated significant increases in screening in several of the practices, we believe the concepts of the GAPS model to be sound and recommend it as a practical structure by which to initiate desired change in a complex organizational system, such as a clinical practice setting. ${ }^{17}$ In addition, our study highlighted the importance of other process variables such as leadership, cohesiveness, resources (including creativity), and shared vision. These variables seemed to influence the interactional process of change, becoming barriers or strengths in the process.

There are limitations to interpreting our results, the most significant being the lack of generalizability resulting from our qualitative design and the nonrepresentative nature of our sample. The qualitative design, however, allowed us to gain a richer, descriptive, in-depth look at the effects of our intervention on a variety of practice types. Second, the intervention limited the extent to which the field worker was involved as a change agent, placing more responsibility on the practices to create change. Third, the limited follow-up period made it difficult to assess whether the practice efforts would translate into long-term change. Fourth, measuring changes on chart audits was not an optimal outcome measure, given their dependence on the accurate recording of service delivery.

\section{References}

1. Eyre H, Kahn R, Robertson RM, et al. Preventing cancer, cardiovascular disease, and diabetes: a common agenda for the American Cancer Society, the American Diabetes Association, and the American Heart Association. Circulation 2004;109:3244-55.

2. Hayward RSA, Steinberg EP, Ford DE, Roizen MF, Roach KW. Preventive care guidelines: 1991. Ann Intern Med 1991;114:758-83.

3. McGinnis JM, Foefe WH. Actual causes of death in the United States. JAMA 1993;270:2207-12.

4. National Cancer Institute. Working guidelines for early cancer detection. Bethesda (MD): National Institutes of Health; 1987.

5. U.S. Preventive Services Task Force. Guide to clinical preventive services: an assessment of the effectiveness of 169 interventions, 1st ed. Baltimore (MD): Williams \& Wilkins; 1989. 
6. U.S. Preventive Services Task Force. Guide to clinical preventive services: an assessment of the effectiveness of 169 interventions, 2nd ed. Baltimore (MD): Williams \& Wilkins; 1996.

7. U.S. Department of Health and Human Services. Healthy people 2010: understanding and improving health. Washington (DC): U.S. Government Printing Office; November 2000.

8. U.S. Public Health Service. Healthy people 2000: national health promotion and disease prevention objectives and healthy schools. J Sch Health. 1991; 61:298-328.

9. Frame PS. Health maintenance in clinical practice: strategies and barriers. Am Fam Physician 1992;45: 1192-200.

10. Lurie N, Manning WG, Peterson C, Goldberg GA, Phelps CA, Lillard L. Preventive care: do we practice what we preach? Am J Public Health 1987;77:801-4.

11. Solberg LI, Kottke TE, Brekke ML, Magnan S. Improving prevention is difficult. Eff Clin Pract 2000;3:153-5.

12. Solberg LI, Kottke TE, Conn SA, Brekke ML, Calomeni CA, Conboy CS. Delivering clinical preventive services is a systems problem. Ann Behav Med 1997; 19:271-8.

13. Grol R. Beliefs and evidence in changing clinical practice. Br Med J 1997;315:418-21.

14. Oxman A, Thomson MA, Davis DA, Haynes RB. No magic bullets: a systematic review of 102 trials of interventions to improve professional practice. Can Med Assoc J. 1995;153:1423-31.

15. Goodwin MA, Zyzanski SJ, Zronek S, et al. A clinical trial of tailored office systems for preventive service delivery. The Study to Enhance Prevention by Understanding Practice (STEP-UP). Am J Prev Med 2001;21:20-8.
16. Miller G. Supplying provider data via the Internet. Health Manag Technol 1998;19:42-44.

17. Dietrich AJ, Woodruff CB, Carney PA. Changing office routines to enhance preventive care: the preventive GAPS approach. Arch Fam Med 1994;3: 176-83.

18. Johnson JD. Selecting ethnographic informants. Newbury Park (CA): Sage Publications; 1990.

19. Bogdewic SP. Participant observation. In: Crabtree BF, Miller WL, eds. Doing qualitative research: multiple strategies. Newbury Park (CA): Sage Publications; 1992.

20. Jorgensen D. Participant observation. Newbury Park (CA): Sage Publications; 1989.

21. Crabtree BF, Miller WL. A qualitative approach to primary care research: the long interview. Fam Med 1991;23:145-51.

22. Gilchrist VJ. Key informant interviewing. In: Crabtree BF, Miller WL, eds. Doing qualitative research: multiple strategies. Newbury Park (CA): Sage Publications; 1992; p. 70-89.

23. Gleick J. Chaos: making a new science. New York: Penguin Books, Ltd.; 1987.

24. Wheatley M. Leadership and the new science: learning about organization from an orderly universe. San Francisco (CA): Berrett-Koehler; 1992.

25. Miller WL, Crabtree BF, McDaniel R, Stange KC. Understanding change in primary care practice using complexity theory. J Fam Pract 1998;46:369-76.

26. Aita V, Dodendorf DM, Lebsack JA, Tallia AF, Crabtree BF. Patient care staffing patterns and roles in community-based family practices. J Fam Pract 2001;50:889.

27. Jaen CR, Stange KC, Nutting PA. Competing demands of primary care: a model for the delivery of clinical preventive services. J Fam Pract 1994;38: $166-71$. 